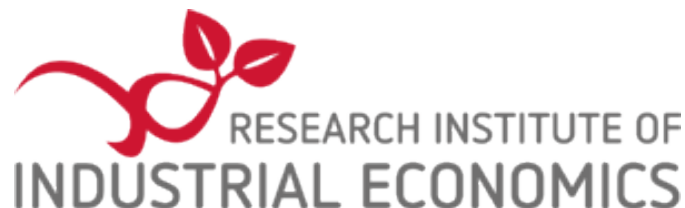

INDUSTRIAL ECONOMICS

IFN Working Paper No. 1051, 2014

\title{
Sickness Absence and Local Benefit Cultures
}

\author{
Assar Lindbeck, Mårten Palme and Mats Persson
}




\title{
Sickness Absence and Local Benefit Cultures*
}

\author{
Assar Lindbeck, \\ Institute for International Economic Studies, Stockholm University, SE-106 91 Stockholm, Sweden \\ and Research Institute of Industrial Economics, Box 55665, SE-102 15 Stockholm, Sweden. \\ Assar.Lindbeck@iies.su.se. \\ Mårten Palme \\ Department of Economics, Stockholm University, SE-106 91 Stockholm, Sweden, and IZA, Bonn, \\ Germany. \\ Marten.Palme@ne.su.se. \\ Mats Persson \\ Institute for International Economic Studies, Stockholm University, SE-106 91 Stockholm, Sweden. \\ Mats.Persson@iies.su.se
}

\begin{abstract}
In many countries, sickness absence financed by generous insurance benefits is an important concern in the policy debate. There are strong variations in absence behavior among local geographical areas. Such variations are difficult to explain in terms of observable socioeconomic factors. In this paper, we investigate whether such variations are related to group effects in the form of social interaction among individuals within neighborhoods. Well-known methodological problems arise when trying to answer this question. A special feature of our efforts to deal with these problems is that we adopt several alternative approaches to identify group effects. Our study is based on a rich set of Swedish panel data, and we find indications of group effects in each of our approaches.
\end{abstract}

Keywords: Income insurance; sick-pay; social norms; neighborhood effects; sickness absence

JEL classification: H56, I38, J22, Z13

\footnotetext{
* We thank two anonymous referees for detailed comments that helped us improve the paper substantially. We are also grateful for comments on previous drafts of the paper from seminar participants at the Economics Department and the Institute for International Economic Studies at Stockholm University, the Research Institute of Industrial Economics in Stockholm, the Economics Department at Uppsala and Oslo Universities, the European Economic Association meeting in Budapest, and the Copenhagen Business School.
} 


\section{Introduction}

Welfare-state arrangements affect individual behavior not only through traditional economic incentives but also through non-economic factors such as group effects, i.e., social processes whereby individuals adjust their behavior to what is regarded as “normal” behavior among their peers. Although group effects have been extensively analyzed theoretically, empirical analysis has been impeded by lack of data as well as by methodological problems. ${ }^{1}$

There is, however, an emerging empirical literature on group effects, dealing with such diverse fields as schooling, criminality, shirking among employees, and the individual's choice of pension plans; see, for instance, Ammermueller and Pischke (2009), Sacerdote (2001), Glaeser et al. (1996, 2003), Ichino and Maggie (2000), and Duflo and Saez (2002, 2003). A few studies of group effects have focused on the utilization of various welfare-state arrangements. For instance, Moffit (1983), Bertrand et al. (2000) and Åslund and Fredriksson (2009) have dealt with the utilization of social assistance (welfare). Rege et al. (2012) have studied the disability insurance, Aizer and Currie (2004) have studied the use of publicly funded maternity care, and Hesselius et al. (2013) have analyzed the consequences for sickness absence of relaxing the requirements for medical certification.

\footnotetext{
${ }^{1}$ For theoretical analyses of the influence of social norms on individual behavior, see, for instance, Parsons (1952), Bicchieri (1990), Manski (1993), Lindbeck (1995) and Lindbeck et al. (1999).
} 
In this paper, we ask to what extent individual differences in sickness absence can be explained by group effects at the neighborhood level. Two stylized facts in the use of the Swedish sick-pay insurance system motivate this research question. First, the utilization rate varies substantially over time, and it is not possible to explain these variations by changes in the rules of the insurance system, the health of the population or conditions on the labor market. Figure 1 shows the average work absence in Sweden between 1955 and 2012. This figure reveals that the average numbers of sick-absence days nearly doubled between 1997 and 2002, and fell by two thirds between 2002 and 2010. It is hard to explain these large fluctuations without some kind of amplifying mechanism, such as a social multiplier.

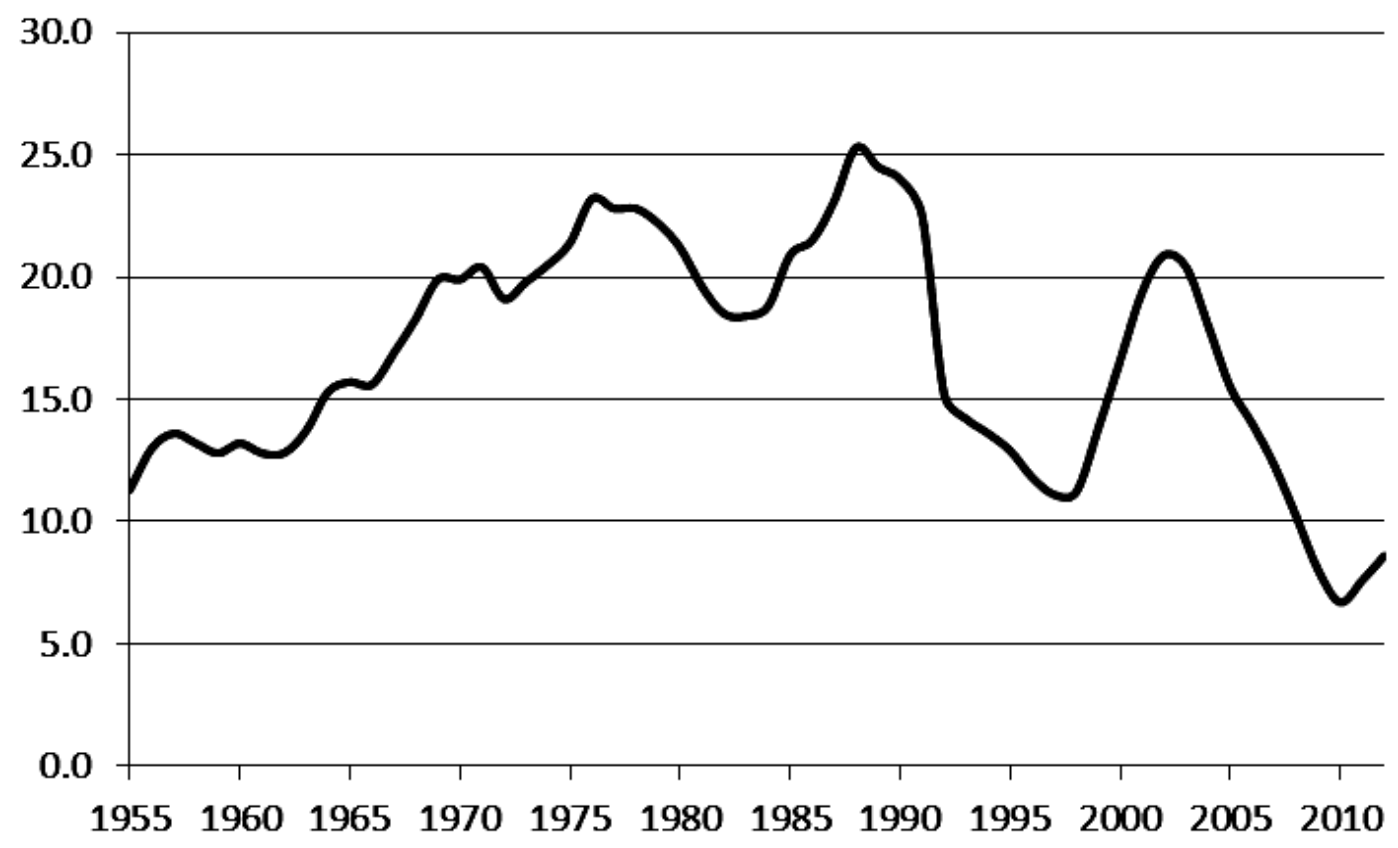

Fig. 1. The average yearly number of days of sickness absence per employee in Sweden, 1955-2012. Source: The National Social Insurance Board. 
The second fact is that there are huge variations in the sickness-absence rate among different geographical areas, even though the workers in these areas participate in the same sick-pay insurance system. This is also the case after controlling for differences in a number of socio-economic factors, such as demographic structure, population health indicators, and labor-market conditions; see Lindbeck, Palme and Persson, 2009). For example, in 2001 the average number of days on sick-pay insurance was 38.9 in the municipality of Jokkmokk and 13.3 in the municipality of Mullsjö. This raises the suspicion that there is a large variation in local social norms, a phenomenon that could be characterized as "local benefit-dependency cultures".

The Swedish sick-pay insurance system consists of two parts: (1) a mandatory, nationwide system, and (2) supplementary occupational arrangements that vary across groups of employees. Several characteristics of the system encourage moral hazard. First, the replacement rates are quite high for a majority of employees (80-90 percent of insured earnings). Second, entering a sick-pay period is basically left to the individual's own discretion since a doctor's certificate is not required for the first week of absence. Third, there is no limit to the number of days that an individual may receive sickness benefits. Fourth, there is evidence that doctors rarely turn down requests for such certificates. For instance, Englund (2008) found that doctors were prepared to provide certification in 80 percent of the cases where they themselves believed that sick leave was either not necessary or could even be harmful to the individual. Even the authorities have found the 
attitude among doctors too lax, and they have subsequently tried to influence doctors to tighten their monitoring. ${ }^{2}$

We define group effects as the individual's adjustment to normal (average) behavior among his or her neighbors. ${ }^{3}$ The basic idea is that daily encounters with neighbors transmit and uphold social norms. Indeed, it is often assumed that social norms are established and enforced through approval and/or disapproval among neighbors (cf. Durlauf, 2004, and Van Ham et al., 2012). To begin with, we present a simple theoretical model of sick-pay insurance with social norms. The model may have multiple solutions, thereby illustrating the possibility that different neighborhoods wind up with different sickness absence rates, even if there are no underlying health differences across neighborhoods. In the empirical analysis, we employ several different approaches to uncover such group effects.

We use a data set including register information on individual utilization of sick-pay insurance for the period 1996-2002 along with information on several other socioeconomic variables. A quite unique feature of our data set is that this information is matched with information about the individual's workplace and neighborhood. This allows us to calculate accurate measures of the average use of sick-pay insurance within each neighborhood and each workplace included in the data.

\footnotetext{
${ }^{2}$ See Engström and Johansson (2012).

${ }^{3}$ Group effects may also pervade other arenas than neighborhoods. For instance, national mass media may influence individuals to adopt behavior regarded as "normal" in the nation as a whole. Social interaction may also take place within country-wide professions or organizations, including workplaces.
} 
There are well-known methodological problems associated with estimating group effects on individual behavior when relying on non-experimental data. We emphasize two problems pointed out by Manski (2000): (i) neighborhoods may be endogenously formed, thus giving rise to omitted-variable bias; (ii) there may be correlated shocks caused by e.g. contagious diseases or major accidents. There is, however, a third problem that is also relevant for our study: (iii) measurement errors may cause attenuation bias. The first two problems will bias the results upwards and the last problem downwards, towards zero.

In our main analysis, we explore the panel structure of our data and use individual fixed effects to deal with problem (i) mentioned above. The identifying information in this analysis comes from two sources: the fact that work absence changes differently among neighborhoods across time, and the fact that people move between neighborhoods with different work-absence rates. To isolate the latter source of variation we also look separately at movers between neighborhoods.

To deal with problems (ii) and (iii) - correlated shocks and attenuation bias from measurement errors - we apply an instrumental variables approach. As an instrumental variable we use the share of private-sector employees living in the neighborhood. The motivation for this choice of instrument is that private firms (for reasons discussed below) have lower sickness absence than public-sector employers. Although the validity of this instrument can be questioned on levels, we argue that it will fulfill the exclusion restriction if combined with individual fixed effects. 
A special problem in studies of group effects is that it is difficult to distinguish between social norms and the dissemination of information. For instance, Duflo and Saez (2002, 2003) emphasize that they are not able to make such a distinction in a study of participation in pension plans by university employees. By contrast, Aizer and Currie (2004) try to make a distinction in their study of participation in publicly funded pre-natal care. They assume that mothers who have previously used such care do have information about the availability of the services. The authors therefore argue that the estimated group effects for such mothers reflect social norms, rather than the transmission of information. We will discuss this possibility later in the paper, where we also consider the conceptual difficulties of distinguishing between norms and information.

We also examine the importance of the strength of networks. Presumably, group effects are stronger in tight networks than in weak ones. First, we use an interaction model as well as a double fixed-effects model to estimate whether there is a stronger social interaction effect if two individuals live in the same neighborhood and work at the same workplace. Second, we ask to what extent sickness absence of newly arrived immigrants, with different ethnic backgrounds, is affected by the work-absence rate among native Swedes in their neighborhood. 


\section{A Model of Geographic Heterogeneity}

When analyzing local differences in sickness absence, it is useful to formulate a hypothesis on how such differences emerge in the first place. For this purpose, our point of departure is the insurance model of Lindbeck and Persson (2013) with a continuous treatment of the individual's ability and willingness to work. By adding social norms to that model, we show that geographic variation may arise even if all individuals are identical ex ante.

Assume a representative individual with a consumption utility function $u(c)$. When working, the individual's utility is

$$
u^{W}=u\left(c^{W}\right)+\theta
$$

where $c^{W}$ is the individual's consumption when working - more specifically, his net wage. Let $\theta$ represent the disutility (when $\theta<0$ ) or utility (when $\theta>0$ ) of working per se. We assume that $\theta$ is a continuously distributed random variable that is unobservable for the insurer. Although $\theta$ could depend on many circumstances, for simplicity we regard it as a health variable that affects the pain of (or pleasure from) work.

When absent from work, the individual lives on benefits from sick-pay insurance and consumes $c^{A}$, yielding consumption utility $u\left(c^{A}\right)$. The insurance contract can then be represented by the vector $\left(c^{W}, c^{A}\right)$. 
Assume now that living on benefits is associated with a stigma, $\phi$. We simply deduct this term from consumption utility when the individual is absent from work:

$$
u^{A}=u\left(c^{A}\right)-\phi
$$

The individual is indifferent between working and staying home when $u^{A}=u^{W}$, i.e., when $u\left(c^{W}\right)+\theta=u\left(c^{A}\right)-\phi$. This equation defines the cut-off $\theta=\hat{\theta}$ between working and being absent from work; the individual stays home from work if the realization of the random health variable is

$$
\theta \leq \hat{\theta} \equiv u\left(c^{A}\right)-u\left(c^{W}\right)-\phi
$$

Let $F(\theta)$ be the distribution function of $\theta$. With ex ante identical individuals, there will be $F(\hat{\theta})$ individuals with realizations of $\theta$ less than $\hat{\theta}$. It follows that total absence in society is

$$
\pi \equiv F\left(u\left(c^{A}\right)-u\left(c^{W}\right)-\phi\right)
$$


Hence, absence $\pi$ depends continuously on the insurance system $\left(c^{A}, c^{W}\right) .{ }^{4}$ Since we have normalized the population size to unity, $\pi$ can be interpreted as either total absence or average absence in society.

Assume now that the stigma of being absent from work is a decreasing function of average (total) absence in society:

$$
\phi=\phi(\pi), \quad \phi^{\prime}(\pi)<0 .
$$

Inserting (5) into (4), we have

$$
\pi=F\left(u\left(c^{A}\right)-u\left(c^{W}\right)-\phi(\pi)\right)
$$

Since both $F(\cdot)$ and $\phi(\cdot)$ may be non-linear, equation (6) may have multiple solutions. This possibility is illustrated in Figure 2, where the left-hand side of (6) is represented by the straight, 45-degree line. The right-hand side is represented by the non-linear curve; it is increasing in $\pi$ since $F(\cdot)$ is increasing, and $\phi(\cdot)$ is decreasing. The way we have drawn the curve, there are three equilibria in the model, i.e., three values of $\pi$ for which (6) is satisfied. In fact, it is well known that models with social interaction, of which social norms are an example, may have multiple solutions; cf. Brock and Durlauf (2001).

\footnotetext{
${ }^{4}$ A sustainable system requires budget balance: $\left(1-c^{W}\right)[1-F(\hat{\theta})]=c^{A} F(\hat{\theta})$, where we have normalized the individual's productivity, when working, to unity.
} 
Even if the RHS of (6) were linear, it is also well known that such a model may display a “social multiplier” (cf. Glaeser et al., 1996 and 2003). In the context of our model, modest changes in the parameters of the insurance system may shift the RHS curve of Figure 1 and generate large changes in the intersections between the RHS and LHS curves, and hence in the absence rate. Moreover, when the model is non-linear, modest changes in the parameters may even cause discrete jumps between low- and high-absence equilibria.

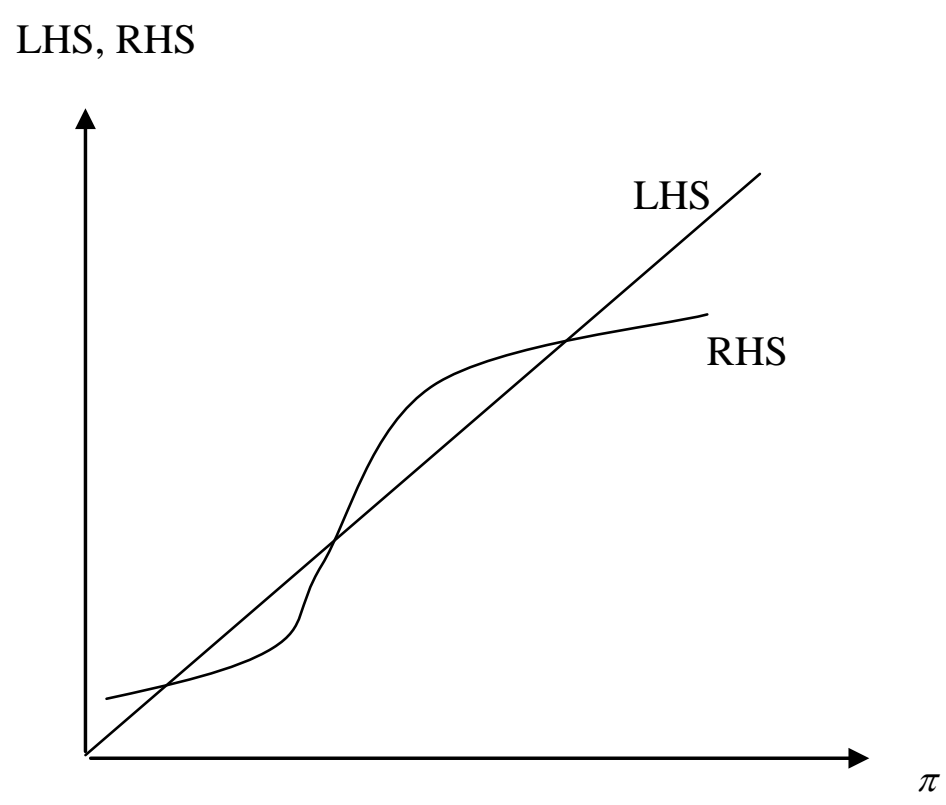

Fig. 2. Multiple solutions of equation (6)

For a given insurance system $\left(c^{A}, c^{W}\right)$, the absence rate $\pi$ may thus not be not unique. Even if a nationwide system is imposed on the whole country, different equilibrium configurations are likely to emerge in different geographical regions. Thus, regions may have different absence rates even when individuals are identical ex ante. Of course, there 
are other possible explanations for regional differences in absence, such as socioeconomic differences. But even after having controlled for such factors, group effects may cause regional absence rates to differ.

\section{Sweden's Sick-Pay Insurance Program and Descriptive Statistics}

The sick-pay insurance program, which replaces foregone earnings due to temporary diseases or other health problems, is one of Sweden's most important income security programs. It is financed through payroll taxes and the expenditures of the program amount to about 2 percent of GDP (see e.g. Johansson and Palme, 2005). As can be seen in Figure 1, the average annual number of sick days per worker replaced by this insurance varies during our period of study (1996-2002) between 11 and 21 days.

The time period of our study, 1996-2002, was mainly determined by data availability. During that period, the sick-pay insurance system underwent some changes, although the basic structure of the system remained intact. During most of this time period, the employer was required to pay the sickness benefits directly to the worker for the first two weeks of each sick-pay spell of absence; after these two weeks, the sickness benefits were paid by the government system. However, during a short period (January 1, 1997 to March 1, 1998), the employer’s responsibility was extended to four weeks, after which the government paid the benefits. 
On top of the government-financed benefits, there are also supplementary benefits from negotiated occupational schemes (provided the worker is covered by a central agreement between the trade unions and the employers' confederation). ${ }^{5}$ The government-financed sick-pay insurance program replaces earnings up to a social security ceiling. ${ }^{6}$ The negotiated occupational plans also have ceilings, but at considerably higher levels.

The replacement rate - the share of foregone earnings replaced by the insurance - has been changed on some occasions in the recent decades. During the period covered by the data used in this study the main change occurred in 1998. Before 1998, the compensation level in the government-run system was, after a first waiting day with no replacement, 75 percent until day 14 in a spell. It was 85 percent between day 15 and day 90 . Then it dropped to 75 percent again at day 91. Since the 1998 reform, it has been 80 percent after the first waiting day until day 14 and 90 percent from day 15.

Our data set combines individual sickness-absence data from the Swedish National Insurance Agency with a large number of socioeconomic variables obtained from the LISA database, compiled by Statistics Sweden. Since we only have information on the use of the national sick-pay insurance, we only observe sickness spells that are longer than 14 days (for the period January 1, 1997 to March 1, 1998, we can only observe spells longer than 28 days). It would, of course, have been desirable to also have data on shorter spells, but benefits paid directly by the employer are not systematically reported. ${ }^{7}$

\footnotetext{
${ }^{5}$ About 95 percent of all workers are covered by central agreements.

${ }^{6}$ See e.g. Palme and Svensson (1999) on the construction of the social insurance ceiling.

${ }^{7}$ In the empirical analysis we performed sensitivity analyses by excluding the years 1996-1998. The reason for excluding 1996, and not only 1997-1998, is that we ran most of the regressions on first differences.
} 
In addition to providing information on numerous individual characteristics, the combined data set allows us to identify each individual's neighborhood and workplace. The data consist of an unbalanced panel for the seven-year period 1996-2002. Although the data set covers the entire population in Sweden, we confine our study to private- and public-sector employees in the age group 18-64, thereby generating about 25 million observations in the entire panel).

A key feature of our data is that we can observe individual records for the entire population. This means that we are able to construct measures of average utilization rates within neighborhoods. Moreover, the reliability of the sick-pay insurance records is very high, since they are based on information from actual transactions from the social insurance administration. However, the fact that we do not record work-absence spells shorter than 14 days has both disadvantages and advantages. The disadvantage is that short work-absence spells are also likely to have neighborhood effects. Not including these may lead to attenuation bias caused by a classical measurement error. The advantage of not including short spells is that we thereby avoid problems of correlated shocks as a result of flu epidemics.

Table 1 reports descriptive statistics for the use of the sick-pay insurance by year. Since we use the share of private-sector workers in the neighborhood as an instrumental

Although the precision in these estimates is, as expected, somewhat less precise than the original ones, the point estimates are very similar. The results from this sensitivity analysis can be obtained from the authors on request. 
variable in the empirical analysis, we break down the data on sector of employment.

Table 1 also reports the number of observations for each year and sector of employment.

Table 1. Average number of days per year compensated by sick-pay insurance, ages 1864.

\begin{tabular}{lcccccccc}
\hline & 1996 & 1997 & 1998 & 1999 & 2000 & 2001 & 2002 & All \\
\hline $\begin{array}{l}\text { Average number of days, } \\
\text { total population }\end{array}$ & 7.11 & 6.03 & 8.06 & 10.16 & 12.47 & 14.56 & 15.31 & 10.61 \\
$\begin{array}{l}\text { Standard deviation, total } \\
\text { population }\end{array}$ & 35.52 & 33.56 & 38.45 & 43.87 & 49.42 & 54.28 & 55.81 & 45.50 \\
$\begin{array}{l}\text { Number of observations, } \\
\text { thousands }\end{array}$ & 3,527 & 3,476 & 3,521 & 3,544 & 3,599 & 3,617 & 3,776 & 25,060 \\
\hline $\begin{array}{l}\text { Average number of days, } \\
\text { public-sector employees }\end{array}$ & 8.28 & 7.15 & 9.90 & 12.74 & 16.03 & 19.02 & 19.39 & 13.07 \\
$\begin{array}{l}\text { Standard deviation, } \\
\text { public-sector employees }\end{array}$ & 38.60 & 36.62 & 42.73 & 49.26 & 56.37 & 62.77 & 63.29 & 50.88 \\
$\begin{array}{l}\text { Number of observations, } \\
\text { thousands }\end{array}$ & 1,602 & 1,545 & 1,521 & 1,488 & 1,449 & 1,443 & 1,454 & 10,503 \\
\hline $\begin{array}{l}\text { Average number of days, } \\
\text { private-sector employees }\end{array}$ & 6.13 & 5.13 & 6.66 & 8.29 & 10.09 & 11.60 & 12.76 & 8.83 \\
$\begin{array}{l}\text { Standard deviation, } \\
\text { private-sector employees }\end{array}$ & 32.72 & 30.86 & 34.78 & 39.41 & 43.96 & 47.58 & 50.39 & 41.10 \\
$\begin{array}{l}\text { Number of observations, } \\
\text { thousands }\end{array}$ & 1,925 & 1,931 & 1,999 & 2,056 & 2,150 & 2,173 & 2,322 & 14,557 \\
\hline
\end{tabular}

Note: These data are from our data set, which contains individual data on spells paid for by the government. Data from other sources, not including individual data, report somewhat different numbers; see for instance the time series in Figure 1.

Table 2 shows descriptive statistics of the control variables included in the study. They are divided into three main categories: individual-specific characteristics, workplace characteristics, and neighborhood characteristics. 
Table 2. Descriptive statistics of the variables included as controls.

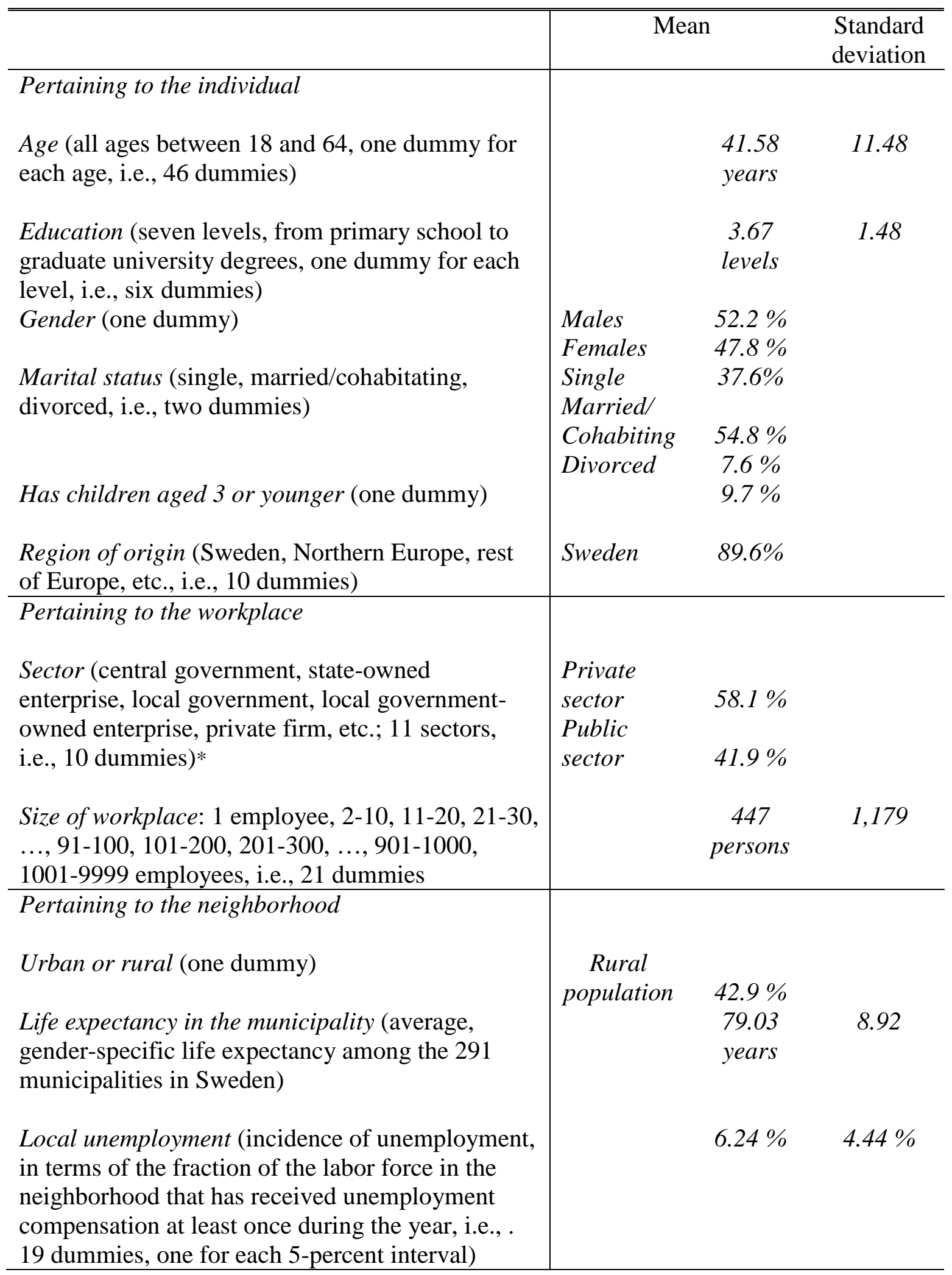


When studying local social norms, a first issue is to select the most relevant geographical domain. Municipalities may be too large for this purpose. We therefore chose to use the so-called Small Area for Market Statistics unit (SAMS) for geographical domains in Sweden. ${ }^{8}$ A SAMS area is defined by individuals living in the same type of housing within the same church parish (for the traditional state-church organization). There are 9003 SAMS in our database. In our main study, we deleted the 403 neighborhoods with fewer than 10 individuals living in them. As a robustness check, we used an alternative sample of SAMS areas with more than two and less than 1,000 individuals. The results from this alternative sample are very similar to those of the main sample and can be obtained from the authors on request.

The average population of the SAMS areas in the main sample is 507 individuals, and the median is 360 . The largest area has a population on 11,980 . The $99^{\text {th }}$ percentile in the population size distribution is 2,824. Figure 3 shows a histogram of the size distribution of all the SAMS areas in the data. In the following, we use the term "neighborhoods" for the SAMS areas.

\footnotetext{
${ }^{8}$ See Statistics Sweden (2005) for a detailed description of this geographical specification.
} 


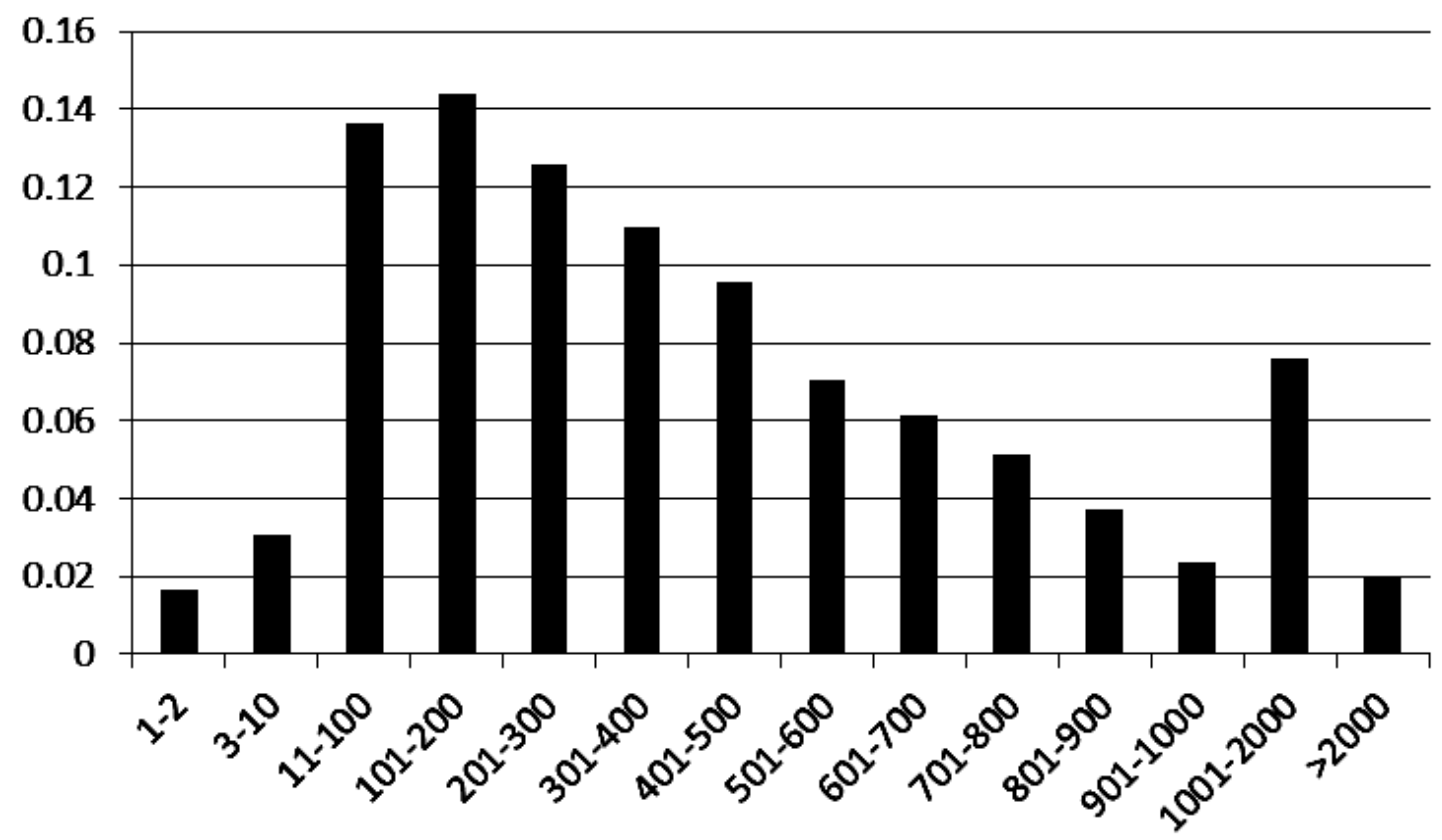

Fig. 3. Histogram for the size distribution (number of individuals) of SAMS areas. Our two alternative samples are $i$ ) all areas with more than 10 individuals; $i$ ) all areas with between 3 and 1000 individuals.

\section{Measuring the Effect of Social Interaction}

Identification of Social Interaction

Our basic hypothesis is that differences in individual use of the sickness-benefit system are causally related to differences in local social norms concerning benefit dependency. As in the theoretical model of Section II, we assume that such norms are related to group behavior, which we represent by the average number of sickness-absence days in a neighborhood. Using a simple linear framework, we estimate the following relation:

$$
S_{i n t}=\alpha+X_{i n t}^{\prime} \beta+\gamma \bar{S}_{n t}+\varepsilon_{i n t}
$$


where $S_{\text {int }}$ is individual i's number of sick-absence days during year $t$. Further, $X_{\text {int }}$ is a vector of observable characteristics of individual $i$ living in neighborhood $n, \bar{S}_{n t}$ is the average absence at time $t$ of the neighbors of individual $i$ and $\varepsilon_{\text {int }}$ represents the effects of individual unobservable characteristics and random events.

Equation (7) may be regarded as a representation of the theoretical model in Section II. Assume there is a number of neighborhoods, each with a total absence rate $\pi_{n}$. An individual $i$ who lives in neighborhood $n$ decides to stay home from work if $u_{i}\left(c_{i}^{A}\right)-\varphi\left(\pi_{n}\right)>u_{i}\left(c_{i}^{W}\right)+\theta_{i}$. Here we have taken into account that individuals may differ both with respect to their preferences $u_{i}(\cdot)$ and with respect to their incomes when working $\left(c_{i}^{W}\right)$ and when absent from work $\left(c_{i}^{A}\right)$. By equation (6), individual $i$ will stay home a fraction of days of the year, $\pi_{i}$, given by

$$
\pi_{i}=F\left(u_{i}\left(c_{i}^{A}\right)-u_{i}\left(c_{i}^{W}\right)-\varphi\left(\pi_{n}\right)\right)
$$

Since $\pi_{i}$ is a fraction of a constant number, namely 365 days a year, the left-hand side of this equation may be expressed in absolute terms, as the number of sick days $S_{i}$. Similarly, we may express the average absence rate in the neighborhood, $\pi_{n}$, in absolute terms as $\bar{S}_{n}$. The utility difference $u_{i}\left(c_{i}^{A}\right)-u_{i}\left(c_{i}^{W}\right)$ may be represented by a number of 
observable characteristics $X_{i}$. In linear form, the above expression for $\pi_{i}$ can thus be written as in (7).

We use two different strategies to empirically highlight the importance of group effects on sickness absence. One is to make a straightforward estimate of $\gamma$ in (7); we refer to this as our "main" strategy, whereby we try to quantify the total group effect. The other strategy involves searching for indications of group effects, by studying the impact of the strength of the individual's network with neighbors on sickness absence.

Both strategies are associated with the econometric problems briefly mentioned earlier:

(i) Unobserved heterogeneity correlated with the average use of sick-pay insurance. Individuals living in the same neighborhood may have similar unobservable characteristics which, in turn, tend to be correlated with the utilization of the sickpay insurance. For example, it is well known that individuals with low socioeconomic status (SES) exhibit both worse health outcomes and higher use of all types of social programs. Since we are not able to observe all aspects of an individual's SES in the data, there may be a bias of the OLS estimates. ${ }^{9}$

(ii) Correlated shocks affecting the use of sick-pay insurance. Many different regional-specific shocks are likely to affect both average and individual use of sick-pay insurance in a neighborhood in the same way. Examples include contagious diseases and major accidents. Regional economic shocks are another

\footnotetext{
${ }^{9}$ This is labeled correlated effects in e.g. Manski (2000).
} 
example; previous research has documented a correlation between the unemployment rate and the use of sick-pay insurance (see e.g. Larsson, 2006). Local unemployment shocks may therefore potentially induce a spurious correlation in model (7).

Our treatment of problem (i) is based on fixed effects. In our main regression, we use individual fixed effects. This means that the variation in $\bar{S}_{n t}$ in (7) comes from (a) individuals who move between neighborhoods (with different absence rates), and (b) changes in neighborhood averages $\bar{S}_{n}$ over time (even if an individual stays in the same neighborhood). In another regression, we restrict the sample to movers between neighborhoods, thereby confining the variation to source (a) only.

Our treatment of problem (ii) adopts an instrumental-variable approach in combination with fixed effects. We use the share of private-sector employees as an instrumental variable. As we show later on (Tables 3 and 4), this share is strongly correlated with average sickness absence in neighborhoods. ${ }^{10}$

\section{Empirical Specification}

Fixed-effects models. First, we extend equation (7) with individual fixed effects, i.e.,

\footnotetext{
${ }^{10}$ In our calculations, we have avoided the so-called "mechanical reflection problem" by excluding the individual from the calculation of the his/her neighborhood average.
} 


$$
S_{i n t}=\alpha_{i}+X_{i n t}^{\prime} \beta_{1}+\bar{X}_{n t}^{\prime} \beta_{2}+\gamma \bar{S}_{n t}+\lambda_{t}+\varepsilon_{\text {int }},
$$

where $\alpha_{i}$ denotes individual-specific fixed effects and $\lambda_{t}$ fixed time effects. $\bar{X}_{n t}$ is a vector whose elements are neighborhood averages of the variables pertaining to the individual, and of the variables pertaining to the workplace in Table 2. In other words, $\bar{X}_{n t}$ consists of the average values of the variables in the upper two thirds of Table 2. ${ }^{11}$

Finally, $\varepsilon_{\text {int }}$ is a random error assumed to be uncorrelated with the average rate of sickness absence in the neighborhood $\left(\bar{S}_{n t}\right)$ conditional on observable characteristics and fixed effects, i.e.,

$$
E\left(\varepsilon_{i n t} \mid \bar{S}_{n t}, X_{i n t}, \bar{X}_{n t}, \alpha_{i}, \lambda_{t}\right)=E\left(\varepsilon_{i n t} \mid X_{i n t}, \bar{X}_{n t}, \alpha_{i}, \lambda_{t}\right)
$$

The identification of this model has two different sources. The first is the fact that the rate of sick-pay insurance use changes differently across neighborhoods over time. The second is the fact that some individuals move between different neighborhoods. Assumption (9) requires that individuals do not sort themselves into neighborhoods over time on the basis of expected changes in sickness absence. It also requires that there are no neighborhood-level shocks of the type mentioned under problem (ii) above, such as

\footnotetext{
${ }^{11}$ The neighborhood variables in Table 2 (i.e., the lower third of the table) are not included in $\bar{X}_{n t}$ since they already appear in the $X_{\text {int }}$ vector.
} 
local flu epidemics. Indeed, flu epidemics have already been excluded by the fact that our data only cover spells of sick leave longer than two weeks.

In a second specification, we restrict the sources of variation to the movers between neighborhoods. Denoting the old neighborhood by $m$ and the new by $n$, we estimate the following version of equation (8):

$$
\begin{aligned}
& S_{\text {int }}^{\text {mover }}-S_{i m, t-1}^{\text {mover }}= \\
& =\left(X_{\text {int }}^{\text {mover' }}-X_{i m, t-1}^{\text {mover' }}\right) \beta_{1}+\left(\bar{X}_{n t}^{\text {all' }}-\bar{X}_{m, t-1}^{\text {all }}\right) \beta_{2}+\gamma\left(\bar{S}_{n t}^{\text {non-mover }}-\bar{S}_{m, t-1}^{\text {non-mover }}\right)+\lambda_{t}^{\prime}+\varepsilon_{i n t}^{\prime} .
\end{aligned}
$$

We use this specification to investigate whether people who move from neighborhood $m$ to neighborhood $n$ adjust their behavior in response to the difference in average absence between these two neighborhoods. Our identifying assumption in this specification is that people who plan to change their absence behavior in the future do not tend to move to neighborhoods with a particular level of average sickness absence. People are thus assumed to move for a variety of reasons (such as changes in family situation, in job prospects, etc.), but not as a result of expected future changes in their own sickness absence.

As discussed under problem (ii) above, an obvious candidate for violation of the conditional exogeneity assumption (9) in models (8) and (10) is the possibility of common neighborhood-level shocks. Even if it is difficult to conceive of such shocks (flu epidemics are basically excluded in the data), we nevertheless take this possibility 
seriously by using an instrumental variable approach. Such an approach will also deal with the attenuation bias caused by measurement errors.

An instrumental variable approach. As indicated above, our motive for using fixed effects is to control for unobserved individual heterogeneity correlated with the average sickness rate in a neighborhood. Our approach to dealing with the possibility of “correlated shocks” is to use an instrumental-variable model combined with fixed effects. We then use the share of private-sector employees in the neighborhood as an instrumental variable.

The rationale for our choice of instrument is that a number of previous studies have shown that public-sector employees have a higher work absence rate than private-sector employees in many countries (see e.g. D’Amuri, 2011, for Italy; see also Table 1 for our data). A plausible explanation is that, since work absence is generally costly for the employer, private-sector employers have stronger incentives to organize their workplaces to avoid high work absence - while public-sector employers often operate under soft budget constraints. It could also be the case that workers with preferences for frequent absence tend to self-select into the public sector.

A key question in this context is, of course, whether our choice of instrumental variable fulfills the exclusion restriction. This issue can be divided into at least two sub-questions. First, is the instrument uncorrelated with neighborhood-level shocks in sickness absence? Indeed, it is very hard to imagine that the share of private-sector employees in a 
neighborhood could be related to any possible shocks. Second, is the instrument uncorrelated with unobserved characteristics related to the average neighborhood level of sickness absence? One possibility for a correlation to exist could be that workers in the private sector with a high sickness-absence rate tend to choose to live in neighborhoods with many public-sector employees. This selection can work through many indirect channels, for instance through housing prices in different neighborhoods.

Although such mechanisms may seem implausible, they cannot be completely dismissed. We therefore deal with this issue by estimating the models on changes rather than on levels. The question then is whether changes in unobservable characteristics of individuals are related to changes in the share of private-sector employees. Such sorting is much less conceivable in the case of changes than in the case of levels. Nevertheless, as a robustness check, we investigate to what extent changes in the neighborhood sickness rate can predict changes in the share of private-sector employees in the neighborhood.

Neighborhood effects: Information vs. social norms. As pointed out in the Introduction, it is often difficult to distinguish between the influence of social norms and the transmission of information. When dealing with this issue, it is useful to distinguish distinction between two types of information. One concerns knowledge about the formal rules of the sick-pay insurance system. The other concerns the actual implementation of the rules by local physicians and administrators. 
It is unlikely that information about the formal rules of the Swedish sick-pay system differs much among individuals. The reason is that the system is mandatory and uniform across the nation; thus it is easy for the authorities to inform citizens about the rules. ${ }^{12}$ Mass media also contribute to spreading this information. It is therefore reasonable to assume that there are very small individual variations in knowledge about the rules of the system. $^{13}$

Information can, however, matter in more subtle ways. Doctors may differ with respect to their propensity to recommend sick leave. Moreover, administrators may apply the formal rules with different degrees of strictness. Neighbors living on sickness benefits may transmit information about the strictness of local doctors and administrators. If so, the transmission of information may be part of the neighborhood effect.

One conceivable way to clarify this issue is to estimate equation (8) on the subset of individuals who are assumed to be well-informed about the functioning of the system, and check whether the estimate of $\gamma$ for that group differs from the estimate of $\gamma$ for the entire population. The well-informed group could, for instance, consist of those who have previous experience of the sick-pay insurance system. The drawback of such an approach is, of course, that those who have earlier experiences of sick-pay insurance may not constitute a random sample of the population. In particular, they might be less healthy than the rest of the population - and may therefore react differently than others to the absence behavior of their neighbors.

\footnotetext{
${ }^{12}$ Immigrants are informed about the details of the social insurance system when they settle in Sweden.

${ }^{13}$ By contrast, the pension plans studied by Duflo and Saez $(2002,2003)$ are quite complicated and difficult to digest; thus the dissemination of information is likely to be important in this case.
} 
Another way to clarify the distinction between norms and information might be to estimate an asymmetric version of equation (10):

$$
\begin{aligned}
& S_{\text {int }}^{\text {mover }}-S_{i m, t-1}^{\text {mover }}=\left(X_{\text {int }}^{\text {mover }}-X_{i m, t-1}^{\text {mover }}\right)^{\prime} \beta_{1}+\left(\bar{X}_{n t}^{\text {all }}-\bar{X}_{m, t-1}^{\text {all }}\right)^{\prime} \beta_{2}+ \\
& +\gamma_{1} \cdot\left(\bar{S}_{n t}^{\text {non-mover }}-\bar{S}_{m, t-1}^{\text {non-mover }}\right)+\gamma_{2} \cdot \delta \cdot\left(\bar{S}_{n t}^{\text {non-mover }}-\bar{S}_{m, t-1}^{\text {non-mover }}\right)+\lambda_{t}+\varepsilon_{i n t}
\end{aligned}
$$

Here, $\delta$ is an indicator variable, defined by

$$
\delta=\left\{\begin{array}{l}
1 \text { if } \bar{S}_{n t}^{\text {non-mover }}>\bar{S}_{m, t-1}^{\text {non-mover }} \\
0 \quad \text { otherwise. }
\end{array}\right.
$$

The interpretation of the coefficients in this equation is that $\gamma_{1}+\gamma_{2}$ captures the effect of moving from a low-absence to a high-absence neighborhood (i.e., $\delta=1$ and $\left.\left(\bar{S}_{n t}^{\text {non-mover }}-\bar{S}_{m, t-1}^{\text {non-mover }}\right)>0\right)$, while $\gamma_{1}$ captures the effect of moving from a high-absence to a low-absence neighborhood (i.e., $\delta=0$ and $\left.\left(\bar{S}_{n t}^{\text {non-mover }}-\bar{S}_{m, t-1}^{\text {non-mover }}\right)<0\right)$.

It would perhaps be tempting to assume that individuals who have moved from highabsence to low-absence neighborhoods have better information than those who have moved in the opposite direction. In such a case, an estimate $\hat{\gamma}_{2}>0$ could be interpreted as an indication that information, rather than norms, matters for group effects. 
This assumption is questionable, however. The formal rules of the insurance system are probably known by almost everyone. Knowledge about local implementation of the rules (i.e., information about doctors and administrators who have a lax attitude toward sickness absence) is not transferable to a new location. Thus, such knowledge becomes obsolete once someone moves to a new neighborhood, and therefore it is more reasonable to interpret an estimate $\hat{\gamma}_{2}>0$ as an indication that it is easier to acquire bad habits than good ones.

Thus, both methods of trying to assess empirically the relative importance of norms and information involve serious problems. There are also conceptual problems inherent in the distinction between norms and information. Assume that a neighbor tells you that doctors in the neighborhood to which you have just moved are very generous in approving certificates for sick leave. Would you interpret this as "pure” information about facts, or would your norms against taking sick leave weaken when you learn that physicians in the neighborhood are generous with sick-leave certificates?

For all these reasons, it is hazardous to distinguish between adjustment to norms and transmission of information - at least when discussing sickness-absence behavior. ${ }^{14}$ Nevertheless, we have run regressions using both methods sketched above.

\footnotetext{
${ }^{14}$ It is conceivable, however, that the distinction might make more sense in other contexts . For instance, in the study of pre-natal care by Aizier and Currie (2004), the distinction between positive and normative information could be relevant.
} 
The Strength of Networks

Earlier we discussed how to estimate the total effect of social interaction. We now turn to an analysis of how the strength of social networks contributes to group effects. We deal with this issue using two alternative approaches. In the first, we exploit the fact that some individuals both live in the same neighborhood and work at the same workplace. We would expect these individuals to have a stronger social network, and thus stronger group effects, than other individuals. For this purpose, we estimate an interaction model with fixed effects for both neighborhoods and workplaces, and we control for the average concentration of people living in the same neighborhoods who also work at the same place. It should be noted, however, that the estimated coefficient in this case does not capture the total social interaction effects from neighbors, since it only reflects the additional effect from working at the same workplace.

In a second analysis we investigate how different groups of immigrants adapt their sickness absence to the average absence among native Swedes in the same neighborhood. The hypothesis is that an immigrant's network with native Swedes is stronger if his/her ethnic background is similar to that of the natives. The parameter estimates are not fully comparable to the previous estimates, since they refer to different groups, but they indicate whether the strength of networks matters for group effects. 
Interaction between neighborhoods and workplaces. Our first analysis of network strength refers to the interaction between neighbors and workplaces. ${ }^{15}$ We estimate the following model:

$$
S_{i n w}=\alpha+X_{i}^{\prime} \beta+v \cdot\left(C A_{i n w} \cdot \bar{S}_{n}\right)+\kappa_{w}+\mu_{n}+\varphi C A_{i n w}+\varepsilon_{i n w}
$$

where the subscript $w$ denotes the workplace. Here, $S_{i n w}$ is the number of days of paid sickness absence of individual $i$, living in neighborhood $n$ and working at workplace $w$. $C A_{\text {inw }}$ is defined as the fraction of the individual's neighbors who are also his coworkers; it can be regarded as a measure of the additional strength of the network facing individual $i$ if he or she belongs to two different networks. The parameters $\kappa_{w}$ and $\mu_{n}$ are fixed effects for workplace and neighborhood, respectively. ${ }^{16}$

The fixed effects $\kappa_{w}$ and $\mu_{n}$ control for variables that are not included in the $X$ vector. $^{17}$ In addition, equation (11) includes the density (concentration) measure $C A_{i n w}$ separately. This allows us to control for the possibility that the strength of the network in itself may be correlated with unobservable characteristics systematically related to the propensity to

\footnotetext{
${ }^{15}$ Another type of interaction between neighborhoods and workplaces is studied by Bayer et al. (2008). More specifically, they show that individuals tend to choose a workplace close to that of their neighbors. ${ }^{16}$ Equation (11) has basically the same analytical structure as the corresponding equation in Bertrand et al. (2000). In an analysis of the use of social assistance ("welfare" in U.S. terminology) among ethnic minorities in the United States, they studied the interaction between language groups and neighborhoods. ${ }^{17}$ The vector $X_{i}$ in (11) is a subset of the previously used $X$ vector, in the sense that neighborhood and work place characteristics have been excluded. The reason is that the neighborhood and workplace variables in $X$ become redundant when we enter neighborhood and workplace fixed effects into the regression equation. The network-intensity variable only varies on the neighborhood/workplace level; we therefore adjust the standard errors for clustering within the cells consisting of the intersection of neighborhoods and workplaces (see e.g. Moulton, 1986).
} 
be absent from work. Our identifying assumption presumes that there is no correlation between the interaction term $C A_{i n w} \cdot \bar{S}_{n}$ and any remaining non-observable variables that affect sickness absence, i.e.,

$E\left(\varepsilon_{i n w} \mid C A_{i n w} \cdot \bar{S}_{n}, C A_{i n w}, \bar{S}_{n}, X_{i n w}, \mu_{n}, \kappa_{w}\right)=E\left(\varepsilon_{i n w} \mid C A_{i n w}, \bar{S}_{n}, X_{i n w}, \mu_{n}, \kappa_{w}\right)$.

The model represented by equation (11) is designed to deal with the problems of both endogeneity and correlated shocks, i.e., items (i) and (ii) in the "list of problems". Our method is to include fixed neighborhood as well as fixed workplace effects. However, measurement errors will still bias the estimated effects towards zero.

The coefficient $v$ in equation (11) has no intuitive interpretation by itself. But it helps us to express the "marginal effect" of the average use of the sick-pay insurance in the neighborhood. Differentiating (11) with respect to $\bar{S}_{n}$ gives $v \cdot C A_{i n w}$ which is the marginal effect on an individual's sickness absence of an increase in the average number of sick days, $\bar{S}_{n}$, in his neighborhood.

As pointed out earlier, this marginal effect does not measure the full effect of social interaction at the neighborhood level. It measures only the magnification of interaction effects when neighbors also meet at the workplace. The fixed neighborhood effect $\mu_{n}$ is a proxy for, among other things, all other possible channels for social interaction at the neighborhood level that we also want to measure in this study. The estimates of $v$ from this model would therefore serve as a conservative "lower bound" for the full effect. 
Immigrant interaction with natives. Our second approach to network strength is to study the behavior of immigrants. ${ }^{18}$ We estimate the following model:

$$
S_{i n t}^{f}=\alpha_{n}+\lambda_{t}+X_{i n t}^{f^{\prime}} \beta_{1}+\bar{X}_{i n t}^{f^{\prime}} \beta_{2}+\gamma \bar{S}_{n t}^{s}+\varepsilon_{i n t}
$$

where $S_{\text {int }}^{f}$ is the number of sick days of immigrant $i$ in neighborhood $n$ at time $t$, while $\bar{S}_{n t}^{s}$ is the average number of sick days among native Swedes in that neighborhood. If immigrants were allocated to neighborhoods in a manner that is uncorrelated with the individual's propensity to call in sick, we could estimate (13) by OLS. In fact, such an allocation may have been the case during the period of study, since most immigrants were refugees, who had been assigned housing by the national authorities. ${ }^{19}$ However, some immigrants may very well have moved later on, in accordance with their own preferences. Although it is unlikely that individual immigrants had knowledge about sickness-absence behavior in different neighborhoods, we cannot rule out some indirect mechanism by which their final residences were correlated with their sickness-absence behavior. To deal with this possibility, we estimate (13) with neighborhood fixed effects. Again, to handle the common shocks problem we use the instrumental variable approach with the share of private-sector employees as instrumental variable.

\footnotetext{
${ }^{18}$ In our data, an immigrant is defined as a person who is born outside Sweden. In a previous workingpaper version of this paper (Lindbeck, Palme and Persson, 2009) we also report results for recent immigrants.

${ }^{19}$ This is the identifying assumption made by Åslund and Fredriksson (2009) in their study of welfare dependency among immigrants.
} 
An advantage of this strategy is that we are able to investigate whether immigrants with a cultural background similar to that of Swedes tend to adjust more than other immigrants to the behavior of native Swedes. The rationale for this question is that such immigrants would be expected to be particularly likely to interact with Swedes. This means that our analysis highlights the importance of the strength of networks, as studied in a different setting earlier in this section.

As we want to examine the transmission of norms from native Swedes to immigrants, it is natural to exclude neighborhoods where immigrants constitute a majority of the population. Indeed, we confine this regression to neighborhoods where the fraction of immigrants is less than 30 percent of the total population. ${ }^{20}$

\section{Results}

\section{Main Results}

Table 3 shows estimates from the model with individual fixed effects (8). For computational convenience, given the very large number of observations, we estimated the model in first differences (FD). Columns 1 and 2 show the estimates when using FDOLS, including and excluding potentially time-varying controls for confounders. We use the confounders presented in Table 2, including neighborhood averages of all the variables pertaining to individuals and workplaces. Columns 5 and 6 show the

\footnotetext{
${ }^{20}$ We also tried 20 and 50 percent; the results are quite insensitive to the choice of cut-off value.
} 
corresponding IV results where the private-sector employment share (PSES) in the neighborhood is used as instrumental variable. The first-stage estimates shown in columns 3 and 4 indicate that the fraction of private-sector employees is a strong instrument for average absence in a neighborhood.

Table 3. First-difference estimates of the effect on an individual's sickness absence (days per year) of a change in the neighborhood's average absence.

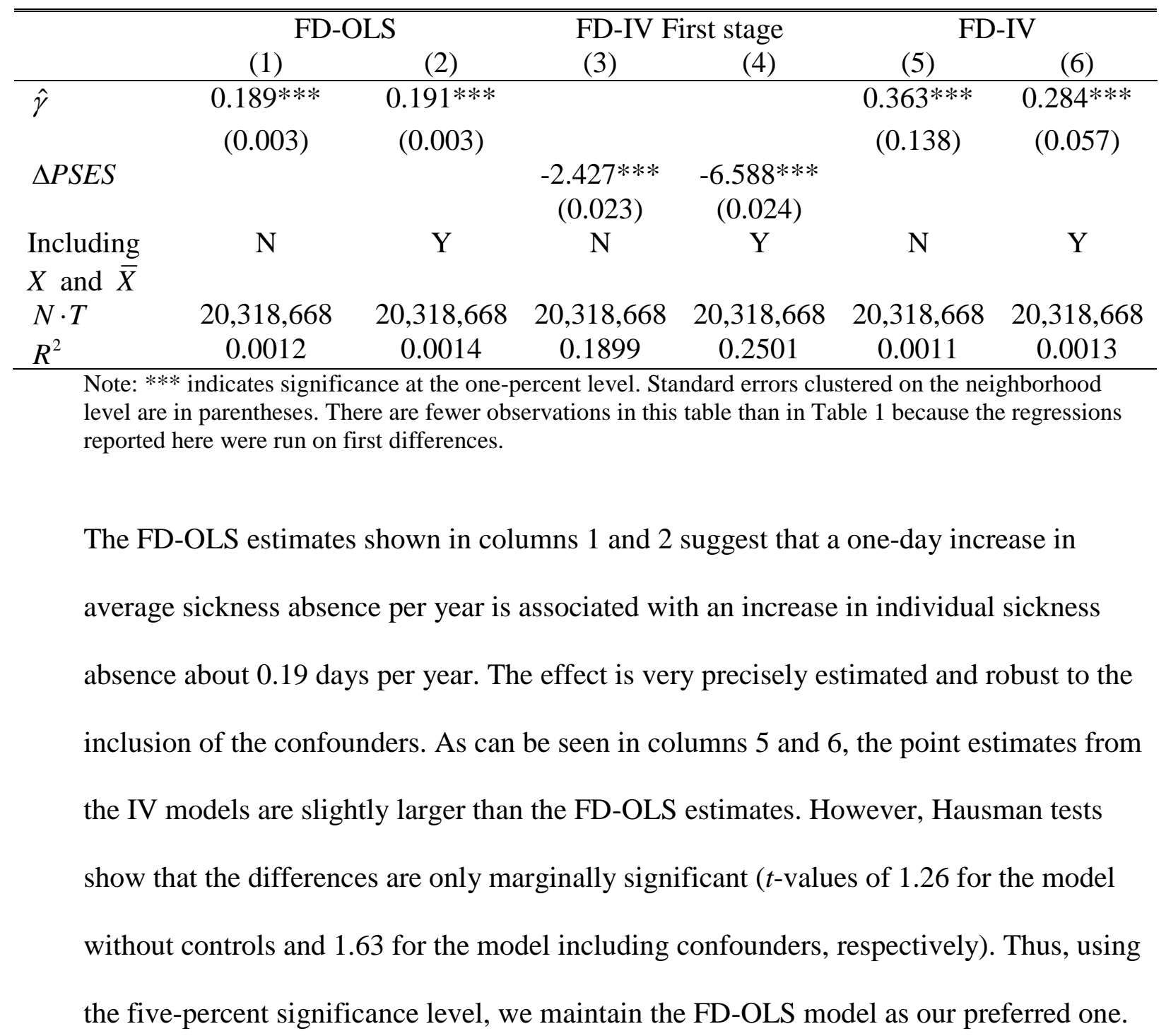


There are at least two possible interpretations of the fact that the OLS and IV estimates are so similar. One is that the attenuation bias from measurement errors in the OLS estimates counteracts the bias caused by neighborhood-level correlated shocks, and that the net effect of these biases is so small that the Hausman test is inconclusive. An alternative interpretation is that both sources of bias are negligible.

We used two different robustness checks. One has to do with the time domain; by excluding the years 1996-1998 from the data, we could check whether our results were driven by the change in the rules of the sickness-insurance system that applied to that year (cf. the discussion at the beginning of Section III above). The other robustness check has to do with the geographical domain; by including very small, and excluding very large, SAMS areas, we could check whether our results are sensitive to the choice of geographical area for social interaction. Using an alternative sample (see Section III) yields essentially the same estimates. It turned out that for both these alternative regressions, the estimates were essentially the same as those reported in Table 3. Moreover, both the OLS and the IV estimates were significant at the one-percent level. ${ }^{21}$

The next question is whether individuals who move from one neighborhood to another adjust their behavior to average sickness-absence behavior in the new neighborhood. Table 4 shows the estimates from equation (10), where we restrict the sample to movers between neighborhoods with different average sickness absence. Columns 1 and 2 show the FD-OLS estimates, which are quite small although significant.

\footnotetext{
${ }^{21}$ The results from these robustness checks are available from the authors on request. We report another type of robustness check in the Appendix.
} 
Let us now turn to the IV specification. The figures in columns 3 and 4 suggest that also for this sample, the fraction of private-sector employees is quite a strong instrument for the average sickness in a neighborhood. Columns 5 and 6 show the IV estimates of $\hat{\gamma}$. Accordingly, an increase in average neighborhood sickness by one day leads to an increase in individual absence by between 0.203 and 0.348 days. These estimates are somewhat smaller than the first-difference estimates for the whole sample reported in Table $3 .^{22}$ One reason is probably that the analysis assumes that individuals who move from one neighborhood to another adjust their behavior within a year. This is hardly realistic, which means that the estimates in Table 4 probably understate the influence of norms.

Table 4. First-difference estimates of the effect on an individual's sickness absence (days per year) of a change in the neighborhood's average absence: movers between neighborhoods.

\begin{tabular}{lcccccc}
\hline \hline & FD-OLS & \multicolumn{2}{c}{ FD-IV First stage } & FD-IV & $(4)$ \\
& $(1)$ & $(2)$ & $(3)$ & $(4)$ & $(5)$ & $(6)$ \\
\hline$\hat{\gamma}$ & $0.110^{* * *}$ & $0.110^{* * *}$ & - & - & $0.348^{* * *}$ & $0.203^{* * *}$ \\
& $(0.006)$ & $(0.007)$ & & & $(0.132)$ & $(0.057)$ \\
$\Delta P S E S$ & & & $-2.414^{* * *}$ & $-6.624^{* * *}$ & & \\
& - & - & $(0.036)$ & $(0.037)$ & - & - \\
Inluding $X$ and $\bar{X}$ & $\mathrm{~N}$ & $\mathrm{Y}$ & $\mathrm{N}$ & $\mathrm{Y}$ & $\mathrm{N}$ & $\mathrm{Y}$ \\
$N \cdot T$ & $2,085,148$ & $2,085,148$ & $2,085,148$ & $2,085,148$ & $2,085,148$ & $2,085,148$ \\
$R^{2}$ & 0.0013 & 0.0016 & 0.0089 & 0.3282 & 0.0012 & 0.0015 \\
\hline
\end{tabular}

Note: *** indicates significance at the one-percent level. Standard errors clustered on the neighborhood level are in parentheses (see Moulton, 1986).

\footnotetext{
${ }^{22}$ Here, too, we made the same robustness checks as we did for Table 3: we tried another time period, and used another set of SAMS areas. Both alternatives yielded estimates that were similar to those reported in Table 4.
} 
The credibility of our IV estimates depends critically on the validity of the private-sector employment share (PSES) as an instrumental variable for the average sickness absence in the neighborhood. However, since our models are just identified, there is no direct way to test for instrumental validity. ${ }^{23}$

The key exclusion restriction for the FE and FD models is that the changes in individual sickness absence do not predict moves to neighborhoods with a higher or lower share of private-sector employees. ${ }^{24}$ A possible mechanism for why a change in health may predict a change of neighborhood could be that housing is cheaper in neighborhoods with a larger share of public-sector employees. Workers who experience more-than-average deterioration in health (and therefore face a fall in disposable income) might move to such neighborhoods. It may, however, be argued that the high replacement rates in Sweden prevent a drastic fall in an individual's disposable income in the case of temporary health problems. Still, we cannot a priori dismiss the possibility that individual health changes may induce a move to other neighborhoods. To test this possibility empirically, we investigate whether or not changes in the propensity for absence are predictive for future changes in PSES values. In other words, do changes in $S_{i}$

\footnotetext{
${ }^{23}$ We also ran regressions corresponding to those shown in Table 3, but on levels (without individual fixed effects) instead of first differences. These regressions yield an estimate of $\gamma$ significantly larger than 1 . This is not credible since it would not yield a stable equilibrium. The exclusion restrictions are not the same for the model on levels as for the FE and FD models. As explained above, the restrictions are more credible in the FE and FD models. These results are presented in Lindbeck et al. (2009).

${ }^{24}$ As for the magnitude of the effects, our results are less conclusive. Based on our main results shown in Table 3, we concluded that the IV estimates were significantly larger than the corresponding firstdifference ones. Under the null hypothesis of valid instruments a natural conclusion of this result is that the effect of measurement errors dominates the effect of common neighborhood level shocks in the firstdifference estimates. An alternative interpretation, however, suggests that our instrumental variables are not strictly valid and/or affected by finite-sample bias (see e.g. Bound et al., 1995), which will bias the results upwards. Since we have no conclusive test for the second possibility, we are not able to discriminate between the two interpretations.
} 
between $t-1$ and $t$ induce changes in PSES between $t$ and $t+1$ ? We estimate the following model:

$$
\operatorname{PSES}_{i m, t+1}-P_{\text {SES }}=\alpha+\beta\left(S_{i n t}-S_{i n, t-1}\right)+\varepsilon_{i n t} .
$$

Table 5 shows the results from this exercise. It can be seen that although the effect is negative and statistically significant, the magnitude of the effect is so small that it is restricted to the sixth decimal. It is unlikely that such a small effect would induce an economically significant bias.

Table 5. Results from a regression of lagged changes in sickness absence on share of private-sector workers.

\begin{tabular}{lc}
\hline \hline & $(1)$ \\
\hline$\Delta S_{i, t-1}$ & $-8.25 \cdot 10^{-6}$ \\
& $\left(1.36 \cdot 10^{-6}\right)$ \\
& \\
$N \cdot T$ & $13,767,569$ \\
$R^{2}$ & 0.0010
\end{tabular}

Note: The specification also includes indicators for age and year.

Our results in Tables 3-5 are consistent with the hypothesis that the average sickness absence in a neighborhood causally affects individual absence. As already mentioned, it is not clear whether such results may be interpreted as reflecting social norms or the transmission of information. Indeed, it is not clear whether such a distinction is reasonable when analyzing group effects in connection with sickness absence. 
To shed some light on this issue, we estimated equation (8) on the subset of individuals who have used the sick-pay insurance program sometime during the period 1996-1998, and we look at their behavior during the period 1999-2002. Table 6 shows the results, with OLS estimates in columns (1) and (2), and IV estimates in columns (3) and (4). While the OLS estimates are of the same order of magnitude as the corresponding estimates in Table 3, the IV estimates in Table 6 are statistically insignificant. Thus, if we were to trust the OLS estimates, most of the group effects could be regarded as reflecting social norms, whereas if we trusted the IV estimates, we would conclude that the information effect dominates.

Table 6. Estimates of equation (8) for those with previous experience of work absence.

\begin{tabular}{lcccccc}
\hline & \multicolumn{2}{c}{ FD-OLS } & \multicolumn{2}{c}{ FD-IV } & \multicolumn{2}{c}{ FD-OLS Movers } \\
\hline & $(1)$ & $(2)$ & $(3)$ & $(4)$ & $(5)$ & $(6)$ \\
$\hat{\gamma}$ & $0.286^{* * *}$ & $0.279 * * *$ & -0.206 & 0.241 & 0.039 & -0.008 \\
& $(0.015)$ & $(0.016)$ & $(0.514)$ & $(0.266)$ & $(0.033)$ & $(0.038)$ \\
Inluding $X$ and $\bar{X}$ & $\mathrm{~N}$ & $\mathrm{Y}$ & $\mathrm{N}$ & $\mathrm{Y}$ & $\mathrm{N}$ & $\mathrm{Y}$ \\
$N \cdot T$ & $2,343,603$ & $2,343,603$ & $2,343,603$ & $2,343,603$ & 217,472 & 217,472 \\
$R^{2}$ & 0.0003 & 0.0006 & 0.0000 & 0.0006 & 0.0005 & 0.0042 \\
\hline
\end{tabular}

Note: *** indicates significance at the one-percent level. Standard errors clustered on the neighborhood level are in parentheses (see Moulton, 1986).

To summarize, the IV estimates in Tables 3 and 6 are consistent with any of the following two hypotheses:

- Neighborhood effects are mainly due to the transmission of information. 
- Norms are important for the population as a whole, but the subgroup of individuals who are often sick is insensitive to norms.

In columns (5) and (6) of Table 6, we show the estimates of equation (10) on the subsample of movers who have previous experience of sickness absence. However, the number of observations is much smaller than in the previous columns, and the precision of the estimates is too low to allow for any conclusions.

Let us now consider the possibility of asymmetric adjustment to norms when individuals move from one neighborhood to another. The hypothesis is that the adjustment is different when someone moves to a neighborhood with higher absence than when he/she moves to a neighborhood with lower absence. Estimating (10') by IV yields the results reported in Table 7 . According to the estimates, $\hat{\gamma}_{1}$ is close to zero, while $\hat{\gamma}_{2}$ is quite large and significant (regardless of whether the $X$ vector is included or not). 
Table 7. Results for IV estimates of equation (10')

\begin{tabular}{lcc}
\hline \hline & $(1)$ & $(2)$ \\
\hline$\hat{\gamma}_{1}$ & 0.006 & $-0.021^{* * *}$ \\
& $(0.007)$ & $(0.008)$ \\
$\hat{\gamma}_{2}$ & $0.275^{* * *}$ & $0.277^{* * *}$ \\
& $(0.018)$ & $(0.018)$ \\
Inluding $X$ and $\bar{X}$ & $\mathrm{~N}$ & $\mathrm{Y}$ \\
$N^{*} T$ & $2,204,170$ & $2,204,170$ \\
$R^{2}$ & 0.0014 & 0.0038
\end{tabular}

Note: *** indicates significance at the one-percent level. Standard errors clustered on the neighborhood level are in parentheses (see Moulton, 1986).

A possible interpretation of the results in Table 7 is that individuals find it easier to adjust to bad behavior among neighbors than to good behavior. However, as we pointed out in Section IV, estimates of an asymmetric equation like (12') do not tell us much about the role of information.

\section{The Strength of Networks}

Interaction between workplace and neighborhood. Table 8 shows the estimates from the interaction model (13), estimated on data from 2002. ${ }^{25}$ It shows not only estimates of the interaction coefficient, $\hat{v}$. The table also reports point estimates of the marginal effects of changes in the average utilization in the neighborhood, $\partial S_{i n w} / \partial \bar{S}_{n}$. (For each individual we have $\partial S_{i n w} / \partial \bar{S}_{n}=v \cdot C A_{i n w}$, but in the table we report only the nationwide average,

\footnotetext{
${ }^{25}$ For computational convenience we do not include the full panel.
} 
i.e., $v \cdot \overline{C A}$.) This number tells us how an increase in the average absence $\bar{S}_{n t}$ in a neighborhood influences individual absence through the interaction between neighborhood and workplace networks.

The estimates of $v$ are significantly different from zero, i.e., we can strongly reject the null hypothesis that individual use of the sick-pay insurance is independent of the average use in the neighborhood. It is also apparent that there is a very small difference between the two specifications - including and excluding controls for individual observable characteristics. As expected, the point estimate of 0.073 is small since it does not reflect the full effects of local interaction, but only the extra effect due to interaction with neighbors who are also workmates. Nevertheless, the estimate is statistically highly significant, thus indicating that there are effects on sickness absence of social interaction, and that the strength of networks is relevant for behavior.

Table 8. Estimates from the interaction model measuring the strength-of-network effect.

\begin{tabular}{lcc}
\hline \hline$\hat{v}$ & $(1)$ & $(2)$ \\
& $3.642^{* * *}$ & $3.421^{* * *}$ \\
$\partial S_{i n w} / \partial \bar{S}_{n}$ & $(0.434)$ & $(0.399)$ \\
$=\hat{v} \cdot \overline{C A}$ & 0.078 & 0.073 \\
$X$ vector included & & \\
$\mathrm{N}$ & $\mathrm{No}$ & Yes \\
$N^{*} T$ & & \\
$R^{2}$ & $3,595,798$ & $3,595,798$ \\
\hline
\end{tabular}

Note: *** indicates significance at the one-percent level. 
Social norms and sickness absence among immigrants. The estimates of the immigrant model (13) are reported in Table 9. The highly significant estimate of the overall effect, estimated on the entire group of immigrants, suggests that a one-day higher work absence rate among native Swedes leads to an increase in the work absence among immigrants of about 0.4 days. Comparing the estimates in columns (i) and (iii) of Table 9, it can be seen that they are remarkably similar and a Hausman test would not reject the null hypothesis of no difference. It should also be noted that they are somewhat larger than the estimates from the previous methods. However, they are obtained on different populations and therefore not fully comparable.

The estimates obtained for immigrants originating from the Nordic countries are significantly larger than those for the entire group of immigrants, thereby suggesting that there is stronger social interaction with the native population among immigrant groups that are culturally close to native Swedes. An overall pattern across the immigrant groups seems to be that the estimates decrease with cultural distance to the Swedish population. Here, then, is further evidence that the strength of networks matters for group effects. ${ }^{26}$

\footnotetext{
${ }^{26}$ Estimating the model on immigrants who have resided in Sweden for one year, two years and three years, respectively, show that the group effect is stronger for those who have lived in Sweden longer (see Lindbeck, Palme and Persson, 2009). This is another indication of the importance of the strength of networks.
} 
Table 9: Estimates of immigrant adjustment to the behavior of natives.

\begin{tabular}{|c|c|c|c|c|c|}
\hline Region & $\begin{array}{l}\text { Number of ind. } \\
\text { and obs. }\end{array}$ & (i) & $\begin{array}{l}\text { mate of } \gamma \\
\text { (ii) }\end{array}$ & (iii) & $\begin{array}{l}P \text {-value, } \\
\text { instrument } \\
\text { first stage }\end{array}$ \\
\hline All regions & $\begin{array}{r}\text { 618,460 ind. } \\
2,756,607 \text { obs. }\end{array}$ & $\begin{array}{l}0.392 * * * \\
(0.0120)\end{array}$ & $\begin{array}{l}0.357^{* * *} \\
(0.0106)\end{array}$ & $\begin{array}{l}0.396 * * * \\
(0.0199)\end{array}$ & 0.000 \\
\hline $\begin{array}{l}\text { Nordic } \\
\text { countries }\end{array}$ & $\begin{array}{l}\text { 193,221 ind. } \\
974,791 \text { obs. }\end{array}$ & $\begin{array}{l}0.602^{* * *} \\
(0.0215)\end{array}$ & $\begin{array}{l}0.562^{* * *} \\
(0.0197)\end{array}$ & $\begin{array}{l}0.786^{* * *} \\
(0.0386)\end{array}$ & 0.000 \\
\hline $\begin{array}{l}\text { EU (except } \\
\text { Nordic } \\
\text { countries) }\end{array}$ & $\begin{array}{l}\text { 72,067 ind. } \\
323,704 \text { obs. }\end{array}$ & $\begin{array}{l}0.318 * * * \\
(0.0320)\end{array}$ & $\begin{array}{l}0.422 * * * \\
(0.0281)\end{array}$ & $\begin{array}{l}0.623^{* * *} \\
(0.0553)\end{array}$ & 0.000 \\
\hline $\begin{array}{l}\text { Europe } \\
\text { (except EU) }\end{array}$ & $\begin{array}{l}\text { 130,641 ind. } \\
588,651 \text { obs. }\end{array}$ & $\begin{array}{l}0.223^{* * *} \\
(0.0269)\end{array}$ & $\begin{array}{l}0.220 * * * \\
(0.0244)\end{array}$ & $\begin{array}{c}0.084^{* *} \\
(0.0419)\end{array}$ & 0.000 \\
\hline Africa & $\begin{array}{l}\text { 28,924 ind. } \\
110,887 \text { obs. }\end{array}$ & $\begin{array}{l}0.166 * * * \\
(0.0496)\end{array}$ & $\begin{array}{l}0.160 * * * \\
(0.0452)\end{array}$ & $\begin{array}{l}0.036 \\
(0.0886)\end{array}$ & 0.000 \\
\hline $\begin{array}{l}\text { North } \\
\text { America }\end{array}$ & $\begin{array}{l}19,886 \text { ind. } \\
81,298 \text { obs. }\end{array}$ & $\begin{array}{l}0.164 * * * \\
(0.0492)\end{array}$ & $\begin{array}{l}0.177^{* * *} \\
(0.0426)\end{array}$ & $\begin{array}{l}0.266 * * * \\
(0.0793)\end{array}$ & 0.027 \\
\hline $\begin{array}{l}\text { Latin } \\
\text { America }\end{array}$ & $\begin{array}{l}\text { 30,158 ind. } \\
126,665 \text { obs. }\end{array}$ & $\begin{array}{l}0.310^{* * *} \\
(0.0536)\end{array}$ & $\begin{array}{l}0.325^{* * *} \\
(0.0459)\end{array}$ & $\begin{array}{l}0.408 * * * \\
(0.0890)\end{array}$ & 0.025 \\
\hline Asia & $\begin{array}{l}\text { 136,059 ind. } \\
518,147 \text { obs. }\end{array}$ & $\begin{array}{l}0.306^{* * * *} \\
(0.0248)\end{array}$ & $\begin{array}{l}0.141^{* * *} \\
(0.220)\end{array}$ & $\begin{array}{l}0.044 \\
(0.0386)\end{array}$ & 0.000 \\
\hline Oceania & $\begin{array}{l}\text { 3,405 ind. } \\
12,951 \text { obs. }\end{array}$ & $\begin{array}{c}0.151 \\
(0.0967)\end{array}$ & $\begin{array}{l}0.270 * * * \\
(0.0869)\end{array}$ & $\begin{array}{l}0.170 \\
(0.1641)\end{array}$ & 0.872 \\
\hline $\begin{array}{l}\text { Former } \\
\text { Soviet } \\
\text { Union }\end{array}$ & $\begin{array}{r}\text { 3,894 ind. } \\
18,926 \text { obs. }\end{array}$ & $\begin{array}{c}0.291 * \\
(0.1547)\end{array}$ & $\begin{array}{l}0.114 \\
(0.1196)\end{array}$ & $\begin{array}{l}-0.063 \\
(0.2328)\end{array}$ & 0.003 \\
\hline \multicolumn{2}{|c|}{ Including $\bar{X}_{n t}$ vector } & Yes & No & Yes & Yes \\
\hline \multicolumn{2}{|c|}{ Including fixed effects $\mu_{n}$} & No & Yes & No & No \\
\hline
\end{tabular}

Note: Three specifications: (i) the $\bar{X}$ vector included; (ii) fixed neighborhood effect; (iii) IV with the $\bar{X}$ vector included. $P$ values for the instrumental variables in the first step of the 2SLS estimates.*** indicates significance at the 1 percent level, ** at the 5 percent level, and * at the 10 percent level. Standard errors clustered on the neighborhood level are in parentheses (see Moulton, 1986). 


\section{Conclusions}

Previous research has shown that variations in the replacement levels and administrative control affect the use of sick-pay insurance programs. ${ }^{27}$ This means that the insurer has viable policy tools to influence sickness absence. If the insured individuals are affected by the sickness-absence behavior in their peer groups, changes in work absence rates are magnified through a social multiplier. This is important to consider when designing a well-functioning social insurance program.

In this paper we study neighborhood effects on sickness absence. We use a theoretical model of sick-pay insurance which includes the possibility of social interaction between individuals, and we show that this model may generate multiple equilibria. Thus, geographical regions that are similar in every respect may nevertheless display different absence rates. In the empirical part of the paper, using a broad range of alternative econometric models, we show that there are significant group effects on the neighborhood level in sickness-absence behavior. The point estimate of the group effect parameter in our preferred model, shown among our main results in Table 3, is 0.19 . This estimate yields a social multiplier $1 /(1-\gamma)$ of 1.23. In other words, a policy-induced change in absence by one percent is boosted by another 0.23 percent.

\footnotetext{
${ }^{27}$ On replacement levels, see e.g. Johansson and Palme, 1996 and 2005, Henrekson and Persson, 2004, or Pettersson-Lidbom and Skogman Thoursie (2013). On control, see e.g. D’Amuri, 2011.
} 
We have made some attempts to distinguish between group effects due to social norms, and group effects due to the dissemination of information. The results are, however, inconclusive. We believe that this does not only reflect econometric problems. In fact, it is conceptually difficult to make such a distinction, at least when we look at social interaction in the context of sick-pay insurance. Moreover, from a policy perspective, the distinction is to some extent irrelevant. 


\section{Appendix: Fixed Effects for Workplaces and Neighborhoods}

Our basic specification (8), reported in Table 3, includes a number of neighborhood characteristics in the $X$ and $\bar{X}$ vectors. As a further robustness test, we also ran a regression of (8) with fixed effects for both neighborhoods and workplaces, including an interaction term between these fixed effects:

$$
S_{i n t}=\alpha_{i}+X_{i n t}^{\prime} \beta_{1}+\bar{X}_{i n t}^{\prime} \beta_{2}+\gamma \bar{S}_{n t}+\kappa_{w}+\mu_{n}+\kappa_{w} \mu_{n}+\varepsilon_{i n t} .
$$

The identification of this model comes from different changes in the use of the sick-pay insurance in the neighborhood/workplace cells. These differences can be driven by changes in the composition of individuals in the neighborhood/workplace cell. The drawback of such a formulation is that part of the effects of norms, that should be represented by $\gamma$, are now absorbed by the fixed effects, $\kappa_{w}, \mu_{n}$ and their product $\kappa_{w} \mu_{n}$. Thus an estimate of $\gamma$ based on such a formulation is likely to understate the full effect of norms. However, an estimate of $\gamma$ that is significantly positive can be seen as an indication that norms do affect sick-absence behavior.

Table A1 below shows the OLS estimates of this model. Again we present results both with and without controls. For computational reasons, we were forced to restrict the sample to a random draw of 60 percent from the original sample covering the period 1996 to 2002. The estimates of $\gamma$ turn out to be significant even for this specification. 
Table A1. OLS results from estimating (8) including fixed effects for neighborhoods, workplaces as well as interactions between neighborhoods and work places.

\begin{tabular}{lcc}
\hline \hline & $(1)$ & $(2)$ \\
\hline$\hat{\gamma}$ & $0.0208^{* * *}$ & $0.0196^{* * *}$ \\
& $(0.0004)$ & $(0.0004)$ \\
Including $X$ and $\bar{X}$ & $\mathrm{~N}$ & $\mathrm{Y}$ \\
$N \cdot T$ & $15,326,736$ & $15,326,736$ \\
$R^{2}$ & 0.0065 & 0.0028 \\
\hline
\end{tabular}




\section{References}

Aizer, A. and Currie, J. (2004), Networks or Neighborhoods? Correlations in the Use of Publicly-Funded Maternity Care in California, Journal of Public Economics 88, 25732585.

Ammermueller, A. and Pischke, J.S. (2009), Peer Effects in European Primary Schools: Evidence from PIRLS, Journal of Labour Economics 27, 315-348.

Åslund, O. and Fredriksson, P. (2009), Peer Effects in Welfare Dependence - Quasiexperimental Evidence, Journal of Human Resources 44, 799-825.

Bayer, P., Ross, S. L. and Topa, G. (2008), Place of Work and Place of Residence: Informal Hiring Networks and Labor Market Outcomes, Journal of Political Economy 116, 1150-1196.

Bertrand, M., Luttmer, E. F. P. and Mullainathan, S. (2000), Network Effects and Welfare Cultures, Quarterly Journal of Economics 115, 1019-55.

Bicchieri, C. (1990), Norms of Cooperation, Ethics 100, 838-886.

Bound, J., Jaeger, D. A. and Baker, R. M. (1995), Problems with Instrumental Variables Estimation when the Correlation between the Instruments and the Endogenous Explanatory Variable is Weak, Journal of the American Statistical Association 90, 443450.

Brock, W. A. and Durlauf, S. N. (2001), Discrete Choice with Social Interactions, Review of Economic Studies 68, 235-260.

D'Amuri, F. (2011), Monitoring and Monetary Incentives in Addressing Absenteeism: Evidence from a Sequence of Policy Changes, ISER Working Paper 2011-10.

Duflo, E. and Saez, E. (2002), Participation and Investment Decisions in a Retirement Plan: The Influence of Colleagues’ Choices, Journal of Public Economics 85, 121-148.

Duflo, E. and Saez, E. (2003), The Role of Information and Social Interactions in Retirement Plan Decisions: Evidence from a Randomized Experiment, Quarterly Journal of Economics 111, 815-42.

Durlauf, S. N. (2004), Neighborhood Effects, in V. Henderson and J. F. Thisse (eds.), The Handbook of Regional and Urban Economics: Cities and Geography, Vol. 4, Elsevier, Amsterdam. 
Englund, L. (2008), Hur har distriktsläkarnas sjukskrivningspraxis förändrats under 11 år? (How has General Practitioners’ Provision of Sick Leave Certificates Changed over 11 Years?), Report, Center for Clinical Research, Falun, Sweden.

Engström, P. and Per Johansson (2012), The Medical Doctors as Gatekeepers in the Sickness Insurance?, Applied Economics 44, 3615-25.

Glaeser, E. L., Sacerdote, B. L. and Scheinkman, J. A. (1996), Crime and Social Interactions, Quarterly Journal of Economics 111, 507-548.

Glaeser, E. L., Sacerdote, B. L. and Scheinkman, J. A. (2003), The Social Multiplier, Journal of the European Economic Association 1, 345-353.

Henrekson, M. and Persson, M. (2004), The Effects on Sick Leave of Changes in the Sickness Insurance System, Journal of Labor Economics 22 , 87-114.

Hesselius, P., Johansson, P. and Vikström, J. (2013), Monitoring and Norms in Work Absence: Evidence from a Natural Experiment, Scandinavian Journal of Economics 115, 995-1019.

Ichino, A. and Maggi, G. (2000), Work Environment and Individual Background: Explaining Regional Shirking Differentials in a Large Italian Firm, Quarterly Journal of Economics 115, 1057-1090.

Johansson, P. and Palme, M. (1996), Do Economic Incentives Affect Work Absence? Empirical Evidence Using Swedish Micro Data, Journal of Public Economics 59, 95-218.

Johansson, P. and Palme, M. (2005), Moral Hazard and Sickness Insurance, Journal of Public Economics 89, 1879-1890.

Larsson, L. (2006), Sick of Being Unemployed? Interactions between Unemployment and Sickness Insurance, The Scandinavian Journal of Economics 108, 97-113.

Lindbeck, A. (1995), Welfare-State Disincentives with Endogenous Habits and Norms, Scandinavian Journal of Economics 97, 477-494.

Lindbeck, A. and Persson, M. (2013), A Continuous Model of Income Insurance, International Tax and Public Finance 20, 961-973.

Lindbeck, A., Nyberg, S. and Weibull, J. W. (1999), Social Norms and Economic Incentives in the Welfare State, Quarterly Journal of Economics 114, 1-35.

Lindbeck, A., Palme, M. and Persson, M. (2009), Social Interaction and Sickness Absence, Working Paper No 2009:4, Department of Economics, Stockholm University. 
Manski, C. F. (1993), Identification of Endogenous Social Effects: The Reflection Problem, Review of Economic Studies 60, 531-542.

Manski, C. F. (2000), Economic Analysis of Social Interactions, The Journal of Economic Perspectives 14, 115-136.

Moffitt, R. (1983), An Economic Model of Welfare Stigma, American Economic Review 73, 1023-1035.

Moulton, B. (1986), Random Group Effects and the Precision of Regression Estimates, Journal of Econometrics 32, 385-397.

Palme, M. and Svensson, I. (1999), Social Security, Occupational Pensions, and Retirement in Sweden, in Gruber, J. and Wise, D. (eds.), Social Security and Retirement around the World, University of Chicago Press, Chicago, Ill.

Parsons, T. (1952), The Social System, Travistock Publications, London.

Pettersson-Lidbom, P. and Skogman Thoursie, P. (2013), Temporary Disability Insurance and Labor Supply: Evidence from a Natural Experiment, The Scandinavian Journal of Economics 115, 485-507.

Rege, M., Telle, K. and Votruba, M. (2012), Social Interaction Effects in Disability Pension Participation: Evidence from Plant Downsizing, The Scandinavian Journal of Economics 114, 1208-1239.

Sacerdote, B. (2001), Peer Effects and Random Assignment: Results for Dartmouth College Roommates, Quarterly Journal of Economics 116, 681-704.

Statistics Sweden (2005), Geography in Statistics - Regional Division in Sweden, Mis 2005:2, Stockholm.

Van Ham, D. M., Bailey, N., Simpson, L. and Maclennan D. (eds.) (2012), Neighborhood Effects Research: New Perspectives, Springer, New York. 